\title{
SNIFFING BY A SILKWORM MOTH: WING FANNING ENHANCES AIR PENETRATION THROUGH AND PHEROMONE INTERCEPTION BY ANTENNAE
}

\author{
C. $\mathrm{LOUDON}^{1}, *$ AND M. A. R. KOEHL ${ }^{2}$ \\ ${ }^{1}$ Division of Biology, University of Kansas, Lawrence, KS 66045, USA and ${ }^{2}$ Department of Integrative Biology, \\ University of California at Berkeley, Berkeley, CA 94720-3140, USA \\ *e-mail: loudon@ukans.edu
}

Accepted 27 June; published on WWW 7 September 2000

\begin{abstract}
Summary
Many organisms increase the air or water flow adjacent to olfactory surfaces when exposed to appropriate chemical stimuli; such 'sniffing' samples fluid from a specific region and can increase the rate of interception of odorant molecules. We used hot-wire anemometry, high-speed videography and flow visualization to study air flow near the feathery olfactory antennae of male silkworm moths (Bombyx mori L.). When exposed to conspecific female sex pheromone, male $B$. mori flap their wings through a stroke angle of $90-110^{\circ}$ at approximately $40 \mathrm{~Hz}$ without flying. This behavior generates an unsteady flow of air (mean speed $0.3-0.4 \mathrm{~m} \mathrm{~s}^{-1}$ ) towards the antennae from the front of

of faster air (at $40 \mathrm{~Hz}$ ) should move between sensory hairs. Calculation of flow through arrays of cylinders suggest that this wing fanning can increase the rate of interception of pheromone by the sensory hairs on the antennae by at least an order of magnitude beyond that in still air. Although wing fanning produces air flow relative to the antennae that is approximately 15 times faster than that generated by walking at top speed $\left(0.023 \mathrm{~m} \mathrm{~s}^{-1}\right)$, air flow through the gaps between the sensory hairs is approximately 560 times faster because a dramatic increase in the leakiness of the feathery antennae to air flow occurs at the air velocities produced by fanning.
\end{abstract} the male. A pulse of peak air speed occurs at each wing upstroke. The Womersley number (characterizing the damping of pulsatile flow through the gaps between the sensory hairs on the antennae) is less than 1 ; hence, pulses

Key words: low Reynolds number, olfaction, insect, antenna, biomechanics, flow, wing, Lepidoptera, silkworm, Bombyx mori.

\section{Introduction}

The interception of chemical signals from the surrounding fluid environment (air or water) often occurs in specialized structures in metazoans, including noses in mammals and antennae in arthropods. A sudden increase in air or water movement across such a chemosensory structure due to muscular or ciliary activity on the part of an organism is sometimes referred to as 'sniffing' and may have either of two related effects on the fluid being sampled: (i) faster fluid movement may decrease the depth of the velocity boundary layer adjacent to the chemosensory surface, thereby increasing the rate of capture of the chemical signal or (ii) sniffing may replace the fluid volume being sampled, i.e. the fluid volume enclosed by or immediately adjacent to the sensory surface (Snow, 1973; Schmitt and Ache, 1979; Atema, 1985; Gleeson et al., 1993). Either of these functions may occur with a simple increase in velocity of flow that is otherwise steady or with periodic fluctuations in velocity. Periodic pulses of increased velocity may have additional significance in minimizing the habituation that might otherwise occur in continuously stimulated chemosensory neurons (Dethier, 1987; Vickers and Baker, 1994).

An increase in the velocity of a signal-laden fluid relative to a chemosensory structure can affect the velocity boundary layer adjacent to that structure. The velocity of a fluid may be assumed to be zero at any surface (the 'no-slip condition'); hence, a velocity gradient ('boundary layer') develops in the fluid near the surface (see Vogel, 1994). The thickness of the velocity boundary layer is usually defined as the distance from the surface at which the velocity reaches $99 \%$ of the freestream value and is a function of the location on the solid surface, its geometry and a dimensionless number, called Reynolds number $(R e)$, that represents the importance of inertia relative to viscosity in the flow:

$$
R e=L U / v,
$$

where $L$ is a characteristic length $(\mathrm{m}), U$ is a characteristic velocity $\left(\mathrm{m} \mathrm{s}^{-1}\right)$, and $v$ is the kinematic viscosity of the fluid $\left(\mathrm{m}^{2} \mathrm{~s}^{-1}\right)$ (see Vogel, 1994). Typically, the larger the $R e$, the thinner the velocity boundary layer is relative to the size of the structure (Schlichting, 1979).

Arthropod antennae vary tremendously in size and shape, but are often cylindrical or composed of arrays of cylindrical sensory hairs (Schneider, 1964; Kaissling, 1971; Zacharuk, 1985; Romoser and Stoffolano, 1994). Flow past sensory 
hairs on arthropod olfactory appendages is usually low-Re flow ( $R e$ of the order of 10 or less, using freestream velocity for $U$ and the diameter of the sensory hairs for $L$ ) (Loudon et al., 1994). At low Re, fluid flow is laminar and there is no turbulent mixing between adjacent streamlines. In such laminar flow, molecular diffusion is the mechanism that moves molecules across streamlines (i.e. that moves molecules laterally as the fluid flows forward). If an olfactory sensor takes up odorant molecules from the surrounding fluid, then the fluid near the surface can become depleted of odorant. The faster the fluid flow past the surface, the steeper the velocity gradient along the surface (i.e. the thinner the velocity boundary layer). When the velocity gradient is steep, the distance across which molecules must diffuse between undepleted ambient fluid and the sensor surface is shorter than when the velocity boundary layer around the sensor is thick.

Although sniffing should decrease the thickness of the velocity boundary layer along a sensory surface, this may not lead to a proportional increase in chemical signal interception. In particular, for low-Re flow, the rate of mass transfer (i.e. molecule movement) between a fluid and a solid usually scales with $R e^{a}$, where $a$ can be of the order of $\leqslant 0.3-0.5$ for cases of external flow around spheres, cylinders or flat plates (Welty et al., 1984). Thus, a doubling of fluid velocity could lead to an increase of only $20-40 \%$ in the rate of chemical signal interception (for $a=0.3-0.5$ ).

An early calculation (Adam and Delbrück, 1968) on the rate of chemical signal interception by a single sensory hair (approximated as an infinitely long cylinder) showed such insensitivity to changes in velocity: a doubling of air speed in the vicinity of the hair from 0.5 to $1 \mathrm{~m} \mathrm{~s}^{-1}$ was predicted to result in an increase of only $40 \%$ in the rate of chemical signal interception (in slower air speeds, the increase would be even less; from equation 47 in Adam and Delbrück, 1968). Later calculations by Murray (1977) for the same isolated hair geometry also predicted a less than proportional increase in rates of chemical signal interception with an increase in velocity. Furthermore, Murray pointed out that a sensory hair in an array is likely to experience slower flow in its vicinity than is an isolated sensory hair because the resistance to fluid flow of the array is greater than that of a single hair. Thus, these models suggest that sniffing would have a fairly modest effect on the interception of chemical signal by structures that may be approximated as single cylinders in low-Re flow.

In contrast, sniffing may have a large effect on chemical signal interception by a chemosensory structure made up of an array of cylinders rather than a single cylinder. For example, a theoretical treatment of flow through an array of two parallel cylinders (Cheer and Koehl, 1987b) predicted a transition between the non-leaky behavior seen when $R e<0.1$ and the very leaky behavior of $R e>0.1$ ('leakiness' is the proportion of fluid approaching a gap in an array that actually passes through) ( $R e$ is calculated using cylinder diameter for $L$ and freestream velocity for $U$ ). This result was empirically verified for pairs of parallel cylinders (Loudon et al., 1994). Models of multiple cylinders in a finite row (for a review, see Koehl, 1995) and of hair-bearing copepod appendages (Koehl, 1995, 1998) also show a transition between non-leaky, paddle-like behavior at hair $R e \leqslant 0.01$ and leaky, sieve-like behavior at $R e>0.1$, as do the real appendages on living copepods (M. A. R. Koehl, unpublished data). Within this range of $R e$, the transition to leaky behavior occurs at lower $R e$ for arrays of hairs that are widely spaced (i.e. that have high $g / d$, where $g$ is the width of the gap between adjacent hairs and $d$ is the hair diameter) (Koehl, 1995). These results suggest that, in this transitional Re range, an increase in the air or water velocity encountered by an antenna bearing an array of hairs can cause a substantial increase in the velocity of flow between the hairs, thereby increasing the rate of arrival of molecules at the hair surfaces (Koehl, 1996).

Insects commonly make movements with their antennae or wings that are thought to change the capture rate or probability of chemical signal interception by the antennae and may be considered to be sniffing (Schneider, 1964). For example, some adult male moths fan their wings vigorously in the presence of sex pheromone released by a conspecific female. Wing fanning by adult males of the oriental fruit moth Grapholitha molesta is correlated with successful mating, suggesting that wing fanning enhances the localization of the pheromone source (Baker and Cardé, 1979).

The purpose of the present study was to test whether wing fanning by moths generates sufficient air flow to cause a transition in the leakiness of their feathery antennae and, thus, an increase in the interception of pheromone. We focused on adult male Bombyx mori (commercial silkworm moths), whose antennae bear rows of chemosensory hairs (sensilla) (Steinbrecht, 1970, 1992) (Fig. 1). Although B. mori rarely fly, adult males fan their wings in the presence of female sex pheromone. Another objective of this study was to compare the wing kinematics of $B$. mori during wing fanning with that of other moth species during flight.

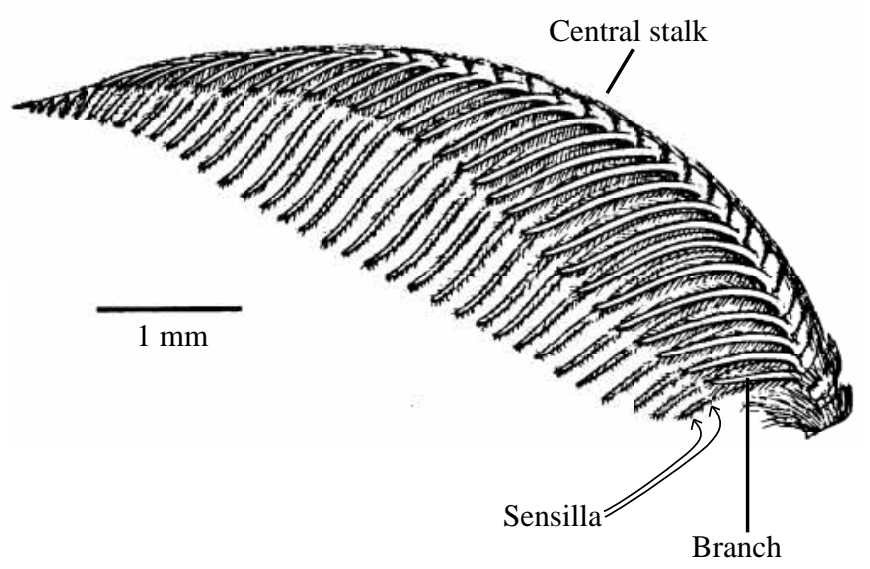

Fig. 1. Anterior view of the right antenna of a male adult moth (Bombyx mori). The two levels of branching can be seen: the sensory hairs (sensilla) are arranged primarily on one side of the branches. 


\section{Materials and methods \\ Rearing and morphometrics of moths}

Silkworm moths Bombyx mori (L.) were purchased from Carolina Biological Supply Company, USA. Larvae were reared in groups in boxes on fresh mulberry leaves using a $16 \mathrm{~h}: 8 \mathrm{~h}$ light:dark cycle at room temperature $\left(21-25^{\circ} \mathrm{C}\right)$. After they had spun cocoons, pupae were isolated in individual meshcovered paper cups to prevent mating by emerging adults.

Morphological variables were measured on 10 male and 10 female adult moths; these individuals were not used for kinematic analysis. Body mass was measured to the nearest $0.001 \mathrm{~g}$ using an analytical balance (Denver Instruments A200DS). The animals were weighed 1-2 days after emergence from their cocoons. The right and left forewings and hindwings were removed from each animal, and their lengths were measured to the nearest $0.1 \mathrm{~mm}$ using vernier callipers; mean forewing and hindwing lengths were calculated for each animal. Wing length was measured from the center of the base of a flattened wing to the farthest point of its perimeter (Fig. 2A). Wing plan area (the area of the dorsal surface) was measured by cutting out and weighing Xerox copies of flattened wings. Each wing was Xeroxed and weighed twice; area measurements were repeatable to the nearest $\mathrm{mm}^{2}$. Both left and right wing areas were measured and averaged.

Wing loading (in $\mathrm{Pa}$ ) was calculated for each moth:

$$
\text { wing loading }=m \boldsymbol{g} / S \text {, }
$$

where $m$ is the mass of the moth $(\mathrm{kg}), \boldsymbol{g}$ is the acceleration due to gravity $\left(9.8 \mathrm{~m} \mathrm{~s}^{-2}\right.$ ) and $S$ is the total plan area (one side) of all four wings on the moth $\left(\mathrm{m}^{2}\right)$. Wing aspect ratio was also calculated for each moth:

$$
\text { wing aspect ratio }=4 R^{2} / S,
$$

where $R$ is the mean length of the four wings on an animal (m) (Brodsky, 1994).

\section{Measurement of wingbeat frequency}

The wingbeat frequency of 15 male moths was measured within 4 days of emergence from their cocoons. Each male moth began to fan its wings vigorously when a female $B$. mori moth was brought into its vicinity (approximately $0.1 \mathrm{~m}$ away in an opaque cup with a mesh top). The wingbeat frequency during wing fanning was determined using a stroboscope (GenRad 1531) to 'freeze' the wing movements visually. Because stroboscopic illumination using integral multiples of the true wingbeat frequency will also result in the appearance of motionless wings, half of this frequency was also checked. For each moth, five readings of wingbeat frequency were made within approximately $1 \mathrm{~min}$; the coefficient of variation of these five measurements averaged $8 \%$ (range 2-18\%, N=15). Wingbeat frequency was measured again in the same way for these same individuals after tethering for anemometry.

\section{Anemometry}

After the wingbeat frequency of each untethered male had been determined as described above, it was tethered by gluing

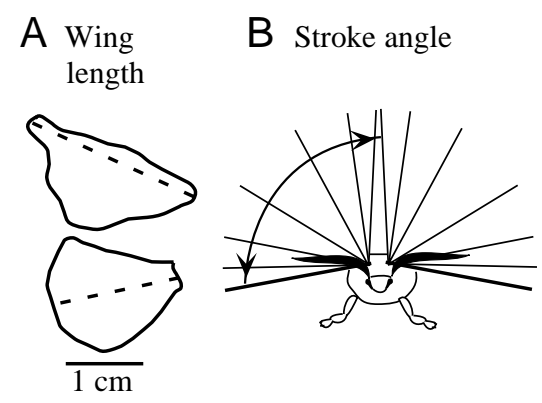

C Angle of attack

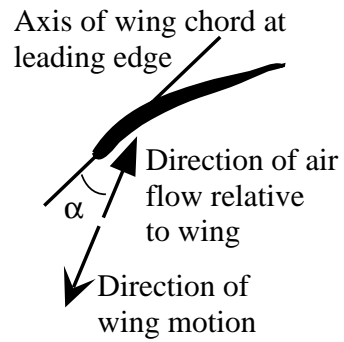

Fig. 2. Diagrams of the morphological and kinematic terms used in the text. (A) Dorsal view of the left pair of wings removed from a male adult moth (Bombyx mori). Wing length (denoted by a broken line) was measured from the center of the wing base to the farthest point on the periphery. (B) The stroke angle is the angle through which the wings move when viewed from the anterior (assuming a vertical stroke plane). (C) Side view of a wing moving through the air. The angle of attack $(\alpha)$ is the angle between the direction of air movement relative to the wing and the angle of the wing chord axis at its current leading edge.

its ventral surface to a wooden cylinder ( $2 \mathrm{~mm}$ in diameter). This cylinder was clamped in place so that the moth and its wooden tether were resting on a horizontal surface covered with black cotton fabric. The edge of the surface was approximately $0.01 \mathrm{~m}$ in front of the anterior of the moth. The probe of a hot-wire anemometer (Thermonetics HWA-103) was placed in front of the moth's antennae. The distance of the probe's wire (which was $3.3 \mathrm{~mm}$ long and $20 \mu \mathrm{m}$ in diameter) from the antennae was measured on video recordings (described below); the mean distance between the wire and the antennal bases was $4.7 \mathrm{~mm}$ (range $2.8-6.1 \mathrm{~mm}, N=15$ ), and the mean distance from the wire to the closest antennal tip was $3.1 \mathrm{~mm}$ (range $0.8-5.1 \mathrm{~mm}, N=15$ ) during the time of the velocity recordings. The slowest air speed that could be measured with this anemometer was $10 \mathrm{mms}^{-1}$. No air movement was detected in the absence of wing fanning, indicating that ambient room air movements near the moths were less than $10 \mathrm{~mm} \mathrm{~s}^{-1}$ during our measurements.

The hot-wire anemometer used to measure air flow in front of the antennae had a frequency response range of $0-2000 \mathrm{~Hz}$. The output from the anemometer was recorded on a Gould 220 Brush chart recorder with the paper moving at its top speed of $125 \mathrm{~mm} \mathrm{~s}^{-1}$. The air speeds plotted on the chart paper were digitized using a Jandel digitizing tablet (Sigma Scan software); on average, 795 points were digitized for $1 \mathrm{~s}$ of recording for each moth (range 513-1268 points) after the chart recorder had accelerated to its top speed (after $1 \mathrm{~s}$ ). Therefore, the Nyquist frequency (the highest frequency that can be resolved with a given sampling interval; see Denman, 1975) was typically approximately $400 \mathrm{~Hz}$. Each chart recorder tracing was digitized on two separate days, and no differences between results from separate digitizing sessions were detected. A spectral analysis was performed on the velocity data from each moth using a program (written by N. D. Pentcheff) based on numerical routines from Press et al. (1988). 


\section{Video recordings of wing fanning}

A Panasonic Palmcorder (model PV-562) was used to make video recordings (SVHS) of the wing motions of the 15 male moths described above under the following conditions: (1) untethered; (2) tethered, with the hot-wire anemometer in position in front of its antennae; and (3) tethered, while smoke from an incense stick $(2.5 \mathrm{~mm}$ diameter $)$ a few centimeters upwind of the moth was used to visualize the air flow patterns generated by wing fanning. All recordings were made at room temperature, which ranged from 22.5 to $24.1^{\circ} \mathrm{C}$ during the recording times. A mirror placed at $45^{\circ}$ relative to the camera lens allowed simultaneous video recording of front and side views of each moth. These recordings were made at standard speed (30 frames s ${ }^{-1}$, two fields per frame).

A Kodak EktaPro TR camera was used to make high-speed video recordings (1000 frames s ${ }^{-1}$, two fields per frame; SVHS) of one male moth (i) to measure wing kinematics with more precision than was possible using the standard-speed video recordings described above and (ii) to quantify the movements of air (labeled with smoke from an incense stick approximately $2 \mathrm{~cm}$ in front of the moth) in relation to the wingbeat cycle. Both air and wing velocities were measured for video sequences of 30 complete downstrokes and 31 complete upstrokes in which identifiable irregularities in the smoke plume allowed estimation of air movement. A complete downstroke or upstroke could be recognized by the reversal of the wing movement at the top and bottom of the wing movement cycle. For this recording, the tethered male moth was suspended horizontally in the air and recorded only from the side.

A Peak Performance motion-analysis system (Peak 5) was used to digitize wing and air movements for both the highspeed and standard-speed videos. The stroke angle (the angle through which the wings move within the stroke plane; Fig. 2B) was measured from images on the standard-speed video tapes. The angle of attack (the angle between the chord of the wing and the direction of wing movement; Fig. 2C) was estimated from images on the high-speed video tapes. Because the shutter speed on the standard-speed video recording was $1 / 60 \mathrm{~s}$, the wings moved through approximately $75 \%$ of their total round-trip excursion during one field. Therefore, on many fields, the two extreme wing positions were captured on a single image (obvious from the opacity of the image of the moving wings), and these fields were used to measure the stroke angle (to the nearest $5^{\circ}$ ). These positions did not differ in location from other fields in which only either the top or the bottom of the two extreme wing positions was visible.

The direction of air movement generated by wing fanning was visualized by marking the air with smoke from a burning incense stick. Because such smoke is positively buoyant in air at room temperature, the horizontal, but not the vertical, velocity component of air was estimated by following its movements.

Calculation of velocity profiles between sensilla

The method of Cheer and Koehl (1987a,b) was used to calculate estimates of velocity profiles between neighboring sensory hairs (sensilla, Fig. 1) of silkworm moth antennae. Calculations of flow through the antenna of a luna moth using a variety of different approaches showed that the model of Cheer and Koehl gave the best match to empirical data for that case (Cheer and Koehl, 1987a). The method of Cheer and Koehl (1987a) used a two-step process to deal with the geometric complexity of the two levels of branching hierarchy seen in many biological structures, including the antennae of the silkworm moth (each antenna is composed of larger branches bearing small sensilla, Fig. 1).

First, the mean velocity between the larger branches, $u_{\mathrm{s}}$, was estimated as if the sensory hairs were not present. $R e$ for the whole antenna, $R \mathrm{e}_{\text {antenna, }}$, was estimated from equation $1 \mathrm{using}$ the width of the antenna $(2 \mathrm{~mm})$ for $L$ and the mean ambient velocity measurement, $u_{\text {ambient }}$, for $U$. When $R e_{\text {antenna }}$ is greater than 1 (see Results), Darcy's law provides a good estimate of the mean flow velocity between the hairless branches, $u_{\mathrm{s}}$. The leakiness $\left(L K_{\mathrm{B}}\right)$ of the hairless branches is given by:

$$
L K_{\mathrm{B}}=\frac{u_{\mathrm{s}}}{u_{\mathrm{ambient}}}=\frac{h^{3} R e_{\text {antenna }}}{d L^{2}},
$$

where $h$ is the gap width between the branches, $d$ is the diameter of the branches and $L$ is the width of the antenna.

We then used $u_{\mathrm{s}}$ as the 'ambient' flow velocity encountered by the small sensory hairs (sensilla) borne on the branches. The $R e$ of a sensillum ( $R e_{\text {hair }}$ ) was calculated using $u_{\mathrm{s}}$ for $U$, sensillum diameter $(2 \mu \mathrm{m})$ for $L$ and the kinematic viscosity of air at $20^{\circ} \mathrm{C}\left(15 \times 10^{-6} \mathrm{~m}^{2} \mathrm{~s}^{-1}\right.$; Vogel, 1994). The leakiness $\left(L K_{\mathrm{S}}\right)$ of the gap between two sensilla with a gap:diameter ratio of 15 was estimated for the appropriate $R e_{\text {hair }}$ using the calculated leakiness between a pair of cylinders presented in Cheer and Koehl (1987b). The two estimates of leakiness made for the two successive levels of branching were then multiplied together to estimate the overall leakiness of the structure:

$$
\begin{aligned}
& \text { overall leakiness }=L K_{\mathrm{B}} \times L K_{\mathrm{S}}= \\
& \qquad \frac{u_{\mathrm{S}}}{u_{\text {ambient }}} \times \frac{u_{\text {gap }}}{u_{\mathrm{S}}}=\frac{u_{\text {gap }}}{u_{\text {ambient }}} .
\end{aligned}
$$

The velocity profile between adjacent sensory hairs may be predicted from an estimate of the mean air speed through a gap between sensilla, $u_{\text {gap. }}$. For $R e_{\text {hair }} \leqslant 0.1$ (corresponding to $u_{\mathrm{s}}<0.75 \mathrm{~m} \mathrm{~s}^{-1}$ ), the velocity profile has a particular shape (see Fig. 6A) (calculated velocity profiles from Cheer and Koehl, 1987b). That is, the ratio between any two points in the gap may be treated as a constant, and the maximum air speed centered between the hairs is 1.2 times the mean air speed through the gap for this gap:diameter ratio.

The morphological characteristics of the antennae used in the calculations, unless indicated otherwise, were: width of antenna, $2 \mathrm{~mm}$; diameter of larger branches, $90 \mu \mathrm{m}$; gap size between larger branches, $125 \mu \mathrm{m}$; sensory hair diameter, $2 \mu \mathrm{m}$; and gap between the sensory hairs, $30 \mu \mathrm{m}$ (measurements from Steinbrecht, 1970, and from our unpublished photomicrographs). Some additional details of this two-step 
estimate follow in the Results; for more information, consult Cheer and Koehl (1987b).

\section{Calculation of the probability of chemical signal interception}

Because the sensory hairs are so small ( $2 \mu \mathrm{m}$ diameter), the flow around them is laminar, low-Re flow. Therefore, the primary mechanism whereby an odorant molecule in the airstream passing between sensory hairs can reach the surface of a hair is by its random thermal motions (these are independent of the bulk air movements). If the distance that an odorant molecule can travel by diffusion in the direction of a hair is large relative to its distance from the sensory hair, then it is more likely to make physical contact with the hair (Fig. 3A); if the diffusion distance is small relative to its distance from the sensory hair, then it is less likely to make physical contact with the hair (Fig. 3B).

To calculate the probability of an odorant molecule reaching the surface of a sensory hair by diffusion once it has entered the gap between adjacent hairs (i.e. crossed the upstream dashed line in Fig. 3), we considered the one-dimensional random walk of odorant molecules perpendicular to the direction of air flow past the hairs. Probabilities were estimated from computer simulations (written using Maple V mathematical software) of an odorant molecule starting at a given location between adjacent sensory hairs and randomly taking steps along the axis joining adjacent hairs (the dashed line in Fig. 3). That sequence was terminated as soon as the molecule reached a hair or until the set time interval $\left(t_{\text {diff }}\right)$ had elapsed. The relevant time interval ( $\left.t_{\text {diff }}\right)$ should be an estimate of how long the air through

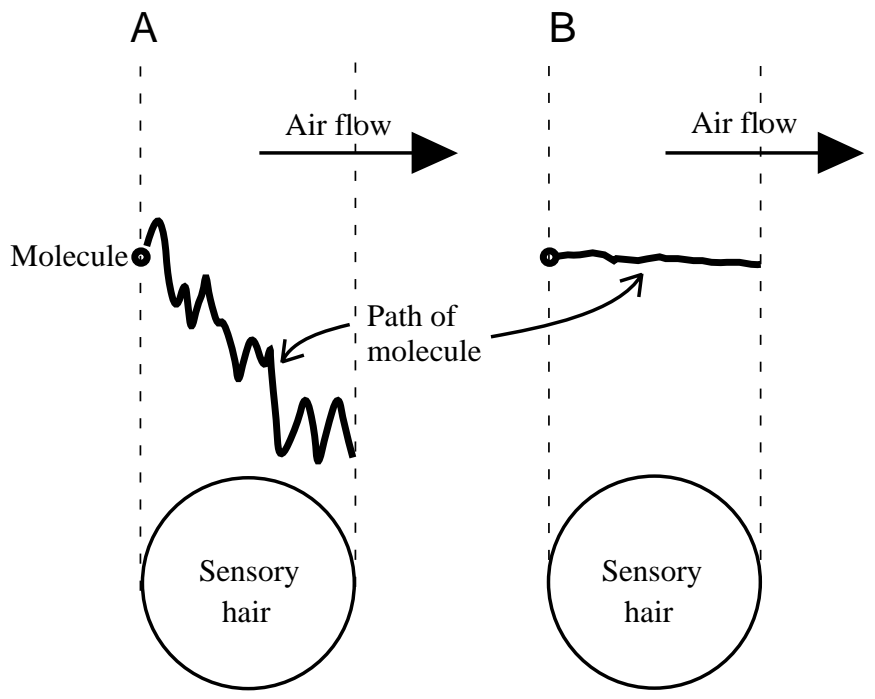

Fig. 3. The probability of a passing airborne chemical signal molecule reaching the surface of a cylindrical sensory hair (seen here in cross section) is a function of the magnitude of its random thermal movements that allow the molecule to cross the streamlines of the air flow. The magnitude of these random thermal movements in the time interval during which the air passes the hair can be large (A) or small (B) compared with the distance of the molecule from the sensory hair. Thus, the corresponding probabilities of interception are high (A) or low (B). which the molecules are diffusing remains in the immediate vicinity of the sensory hairs, which depends on the velocity profile of the air moving between neighboring hairs. We used our calculated velocity profiles between hairs to estimate $t_{\text {diff: }}$ we divided the gap between neighboring hairs into 30 discrete intervals and used the midpoint velocity in each interval $(u)$ to calculate the time $\left(t_{\text {diff }}\right)$ required for a parcel of air in that interval to move past a hair $2 \mu \mathrm{m}$ in diameter $\left(t_{\mathrm{diff}}=2 / u\right)$. The molecules entering the gap between adjacent sensory hairs within a particular spatial interval have a probability of reaching either hair during that time that can be estimated from the proportion of simulated walks that result in a 'hit' of either hair. Whenever a molecule's random walk carried it across streamlines into a new spatial interval with a different $u$, the value of $t_{\mathrm{diff}}$ was adjusted proportionally. Note that the random thermal movements of the molecules parallel to the air flow are ignored; this is equivalent to assuming that the patch of odorant is large relative to the size of the gap such that, on average, as many molecules diffuse out of the gap as diffuse into it along the axis parallel to the flow. These estimates compute the probability of an odorant molecule reaching any location on the surface of the sensory hair. Whether an odorant molecule adsorbs onto the surface of the sensory hair and diffuses on that two-dimensional surface to the pores through the cuticle (Adam and Delbrück, 1968; Murray, 1977; Futrelle, 1984) or remains primarily airborne before striking a pore is still not resolved.

The one-dimensional method described above for estimating molecule encounters with sensory hairs is a simple approximation for the actual three-dimensional case. Convection/diffusion problems in three-dimensional cylindrical arrays are often treated as two-dimensional because the cylindrical elements are much longer than they are wide, and the velocity component in the dimension parallel to the cylinders' length can be ignored to a first approximation (e.g. Fuchs, 1964). For most biological filters with complex geometries, a complete three-dimensional flow field has not been determined, although the velocity profile in the gap between adjacent cylinders can be estimated using the method of Cheer and Koehl (1987b). For such cases, the onedimensional approximation described above for estimating molecule capture would be useful. Therefore, we compared the results of our one-dimensional approximation with those of a two-dimensional simulation for several test cases: cylinder $R e$ values corresponding to those of sensilla on silkworm moth antennae during walking $\left(R e=7.8 \times 10^{-11}\right.$ based on sensillum diameter and mean velocity through the gap between hairs), during wing fanning $\left(R e=4.4 \times 10^{-8}\right)$ and at a higher $R e$ $\left(R e=2 \times 10^{-7}\right)$ than those used by the animals. We calculated the low-Re two-dimensional flow fields from Fuchs (1964; equations 34.2), and then multiplied the magnitudes of all velocities by a constant so that the flow between the cylinders matched the leakinesses predicted from Cheer and Koehl (1987b). In the two-dimensional simulations, the molecules were allowed to wander as far away as $200 \mu \mathrm{m}$ (i.e. 100 cylinder diameters) upstream or downstream of the cylinder before terminating their random walk. The predicted interception rates 
for the one-dimensional method were within $12 \%$ of the twodimensional simulation results for the walking case and within $7 \%$ for the wing fanning case $(N=500$ random walks for each case), but differed more from the two-dimensional results for the Re that was higher than those used by the moths (within $25 \%$ for $\left.R e=2 \times 10^{-7}\right)$. Therefore, our one-dimensional approximation gives a reasonable estimate of molecule capture for the case of the silkworm moth antenna, for which only the velocity profile between adjacent sensilla is available.

The step length and frequency for the simulated random walks were determined from the diffusion coefficient, $D$, the molecular mass of the odorant molecule and the temperature, as explained by Berg (1993). The simulated step length was $4.9 \times 10^{-8} \mathrm{~m}$, and steps were taken every $4.8 \times 10^{-10} \mathrm{~s}$. Five hundred random walks were used for each of the 30 spatial intervals between sensory hairs for each velocity and morphological configuration. The relevant diffusion coefficient $(D)$ depends on the chemical signal molecule, the medium through which it diffuses, the temperature and the pressure. We calculated probabilities using the $D$ for bombykol, a 16-carbon unsaturated alcohol that is the primary molecular component of the sex pheromone for B. mori (Mayer and McLaughlin, 1991). Adam and Delbrück (1968) have estimated, on the basis of its molecular mass $\left(238 \mathrm{~g} \mathrm{~mol}^{-1}\right)$ and chemical functional groups, that the value of $D$ for bombykol in air at $20^{\circ} \mathrm{C}$ and a barometric pressure of $101.3 \mathrm{kPa}$ (1 atmosphere) is $2.5 \times 10^{-6} \mathrm{~m}^{2} \mathrm{~s}^{-1}$.

\section{Results Morphology}

Mean wing length, area, loading and aspect ratio for adult male and female silkworm moths are listed in Table 1. These values lie within the range for other lepidopteran species that fly (for a review, see Brodsky, 1994).

\section{Fanning frequency and air speed}

Untethered male moths in the presence of a female moth fanned their wings at a mean frequency of $42 \mathrm{~Hz}$ (range $35-45 \mathrm{~Hz}, N=15$; measured with the stroboscope). Fanning at such frequencies generated air flow in front of the antennae at speeds of $0.3-0.4 \mathrm{~m} \mathrm{~s}^{-1}$, as measured on the same individuals after they had been tethered (Fig. 4). Six male moths showed a decrease in fanning frequency below this range after tethering (Fig. 4); five of these six had eclosed to adults within 1 day of these experiments. Air speed in front of the antennae was positively correlated with the wingbeat frequency (Fig. 4, linear regression: $r^{2}=0.64, P=0.0004, N=15$ ).

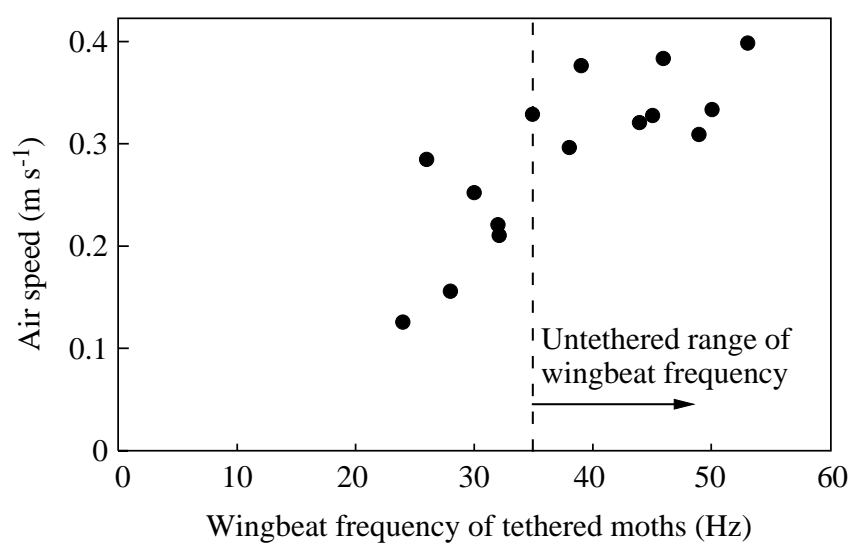

Fig. 4. The air speed in front of the antennae (measured with a hotwire anemometer) was positively correlated with the wingbeat frequency (measured with a stroboscope) for 15 tethered male moths $\left(r^{2}=0.64, \quad P=0.0004\right)$. The wingbeat frequencies of the same individuals prior to tethering were always $35 \mathrm{~Hz}$ or greater; therefore, the air speed generated by wing fanning in untethered male moths is estimated to fall within the range $0.3-0.4 \mathrm{~m} \mathrm{~s}^{-1}$.

There was an unsteady component to the air speed measured by the hot-wire anemometer in front of the antennae; this oscillation in velocity corresponded to the measured wingbeat frequency. The amplitude of the unsteady component (half the peak-to-peak height difference) varied from $6 \%$ (Fig. 5A) to $32 \%$ (Fig. 5B) of the average air speed; the mean amplitude of the oscillations was $16 \%$ of the corresponding mean air speed $(N=15)$. Spectral analysis of the digitized anemometer output for each animal showed that there was a single dominant frequency in the unsteady velocity component; this frequency was the same as the wingbeat frequency for the tethered animal determined using a stroboscope.

\section{Wing kinematics}

Analysis of both standard-speed and high-speed video recordings revealed that the wing movements of a male silkworm moth when fanning were qualitatively similar to those of other moths when flying. All four wings moved together in phase during fanning. Stroke angles measured on animals viewed from the front varied with time, but always ranged between 90 and $110^{\circ}$ for all the moths during vigorous fanning, whether tethered or not. The tip of the forewing traced a figure of eight when viewed from the side (Fig. 5). At the top of the upstroke, the dorsal surfaces of the right and left wings were parallel to each other and touched. The right and left

Table 1. Mean wing and body characteristics for male and female Bombyx mori adults

\begin{tabular}{|c|c|c|c|c|c|c|c|}
\hline \multirow[b]{2}{*}{ Gender } & \multirow{2}{*}{$\begin{array}{l}\text { Total live body } \\
\text { mass }(\mathrm{g})\end{array}$} & \multicolumn{2}{|c|}{ Wing length (mm) } & \multicolumn{2}{|c|}{ Wing area $\left(\mathrm{mm}^{2}\right)$} & \multirow{2}{*}{$\begin{array}{l}\text { Wing loading } \\
(\mathrm{Pa})\end{array}$} & \multirow{2}{*}{$\begin{array}{l}\text { Aspect } \\
\text { ratio }\end{array}$} \\
\hline & & Forewing & Hindwing & Forewing & Hindwing & & \\
\hline Male & $0.396 \pm 0.0921$ & $21.2 \pm 1.00$ & $15.2 \pm 0.75$ & $139 \pm 15.1$ & $129 \pm 19.1$ & $7.2 \pm 1.32$ & $2.6 \pm 0.14$ \\
\hline
\end{tabular}

Values are means \pm S.D. $(N=10)$. 

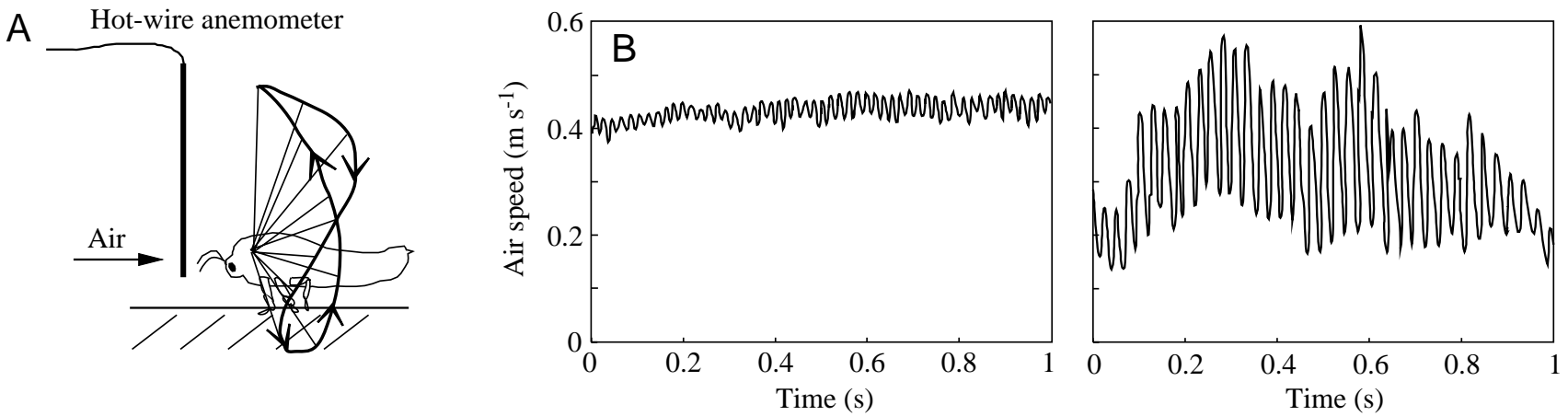

Fig. 5. (A) Diagram showing the approximate position of the hot-wire anemometer in front of the moth's antennae as seen in side view. The generated air flow reaches the moth's antennae from an anterior direction. The trajectory traced by the forewing tip is shown. (B) The air speed recorded by the hot-wire anemometer was unsteady, with a frequency that corresponded to the wingbeat frequency. The amplitude of the unsteady component of air speed varied between moths. The two tracings shown here are the extreme examples of 15 recordings.

wings then peeled away from each other as they moved posterio-ventrally. The wings then rotated so that their anterior margins tipped ventrally, and the wings moved anterioventrally with a small angle of attack during the rest of the downstroke. At the end of the downstroke, the wings rotated so that their anterior margins tipped dorsally, and the wings moved upwards and backwards. Although difficult to measure precisely, the angle of attack during the upstroke was clearly higher than during the downstroke such that the wings appeared to be rowing during the first half of the upstroke. During the final half of the upstroke, the dorsal surfaces of the left and right wings were moved towards each other as they were moved in an anterior direction.

\section{Flow visualizations}

Analysis of high-speed video recordings of smoke tracks revealed which phases of the wingbeat cycle correlated with which phases of the unsteady air flow produced during fanning. The horizontal component of smoke velocity was measured for the median point in time of each downstroke and upstroke sequence digitized. The horizontal velocity component was always directed towards the moth, but was significantly faster during the upstroke than during the downstroke (one-way analysis of variance, ANOVA: $P=0.009, N=61$ ).

Analysis of the smoke movement recorded in standardspeed video recordings revealed a consistent pattern of air movement around all 15 male moths when fanning. When a moth fanned its wings, the air was funneled from the front and sides of the animal into a stream that passed over its dorsal midline. Smoke originating from any point on a line passing approximately $10 \mathrm{~mm}$ in front of the moth was drawn in from a 'capture zone' that extended at least $70^{\circ}$ to each side from the center of the front of the animal's body (i.e. a total angle of $140^{\circ}$ ); this was the maximum lateral excursion visible on the video recordings, so the capture zone of the animals could have been even larger.

When the moths drew smoke directly into their antennae, they changed their fanning behavior. They usually ceased beating their wings momentarily, which resulted in an immediate slowing of the air passing across the antennae. Hence, they stopped ventilating their olfactory receptors when they encountered a presumably noxious smell. In one case, a moth changed its wing movements in a way that reversed the air flow: the smoke was blown in an anterior direction at a mean horizontal speed of $56 \mathrm{~mm} \mathrm{~s}^{-1}$ for $0.4 \mathrm{~s}$. Functionally, this reversal of air flow was like a sneeze, clearing the antenna of the smoky air.

\section{Velocity profiles}

For the measured ambient air speed of $0.35 \mathrm{~m} \mathrm{~s}^{-1}$ generated by wing fanning, we predict a mean air speed between adjacent sensory hairs on an antenna of the order of approximately $0.022 \mathrm{~mm} \mathrm{~s}^{-1}$. This overall leakiness of approximately $6 \%$ was estimated by the two-step method (Cheer and Koehl 1987a,b; see Materials and methods) and is comparable with the leakiness measured directly on luna moth antennae (Vogel, 1983). Re for the whole antenna,

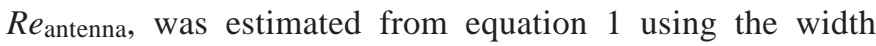
of the antenna, $2 \mathrm{~mm}$, for $L$, and the mean anemometer reading, $0.35 \mathrm{~m} \mathrm{~s}^{-1}$, for $U$. Because $R e_{\text {antenna }}$ exceeded 1 $\left(R e_{\text {antenna }}=47\right)$, the leakiness of the branches on the antenna (ignoring the sensilla) was calculated using equation 4 to be 0.25 . This results in an estimate of $0.088 \mathrm{~m} \mathrm{~s}^{-1}$ for $u_{\mathrm{s}}$ $\left(0.35 \mathrm{~m} \mathrm{~s}^{-1} \times 0.25\right)$. The leakiness of a $30 \mu \mathrm{m}$ gap width between sensilla $2 \mu \mathrm{m}$ in diameter for a $u_{\mathrm{s}}$ of $0.088 \mathrm{~m} \mathrm{~s}^{-1}$ is approximately 0.25 (see Fig. 5A in Cheer and Koehl, 1987b). Therefore, the overall leakiness of the antenna is estimated to be approximately 0.062. Similar calculations for an antenna exposed to an ambient air speed of $23 \mathrm{~mm} \mathrm{~s}^{-1}$ generated by walking (Kramer, 1986) without wing fanning yielded a much lower overall leakiness of only 0.002 .

\section{Probability of chemical signal interception}

The probability of pheromone molecules reaching either hair due to random thermal movements as they pass through the gap is a function both of their location in the gap and the air speed through the gap (Fig. 6B). Note that, in very slow air flow $\left(1 \mathrm{~mm} \mathrm{~s}^{-1}\right.$ average air flow within the gap), molecules at 


\section{C. Loudon And M. A. R. KoeHL}

every position between the sensilla have a high probability of reaching either hair because of the long time that the air takes to pass the $2 \mu \mathrm{m}$ hair. In contrast, at a faster air current of $100 \mathrm{~mm} \mathrm{~s}^{-1}$, only the molecules immediately adjacent to the hairs have a high probability of reaching either hair.

A dimensionless number that describes the relative importance of bulk flow versus diffusion for the movement of molecules is the mass transfer Péclet number, Pé, where:

$$
P e ́=U L / D
$$

(Probstein, 1989; Vogel, 1994). Using the gap width as the characteristic length $L$ and the mean air speed through the gap for the characteristic velocity $U, P e_{\text {gap }}$ calculated in this manner has a magnitude less than 1 for the behaviors occurring in this non-flying species (Fig. 6). Therefore, transport of pheromone within the gaps between sensilla is dominated by diffusion during both walking and wing fanning.

Although a smaller proportion of the pheromone molecules in a parcel of air traveling through the gap between sensilla have time to diffuse to either of the sensilla when the air
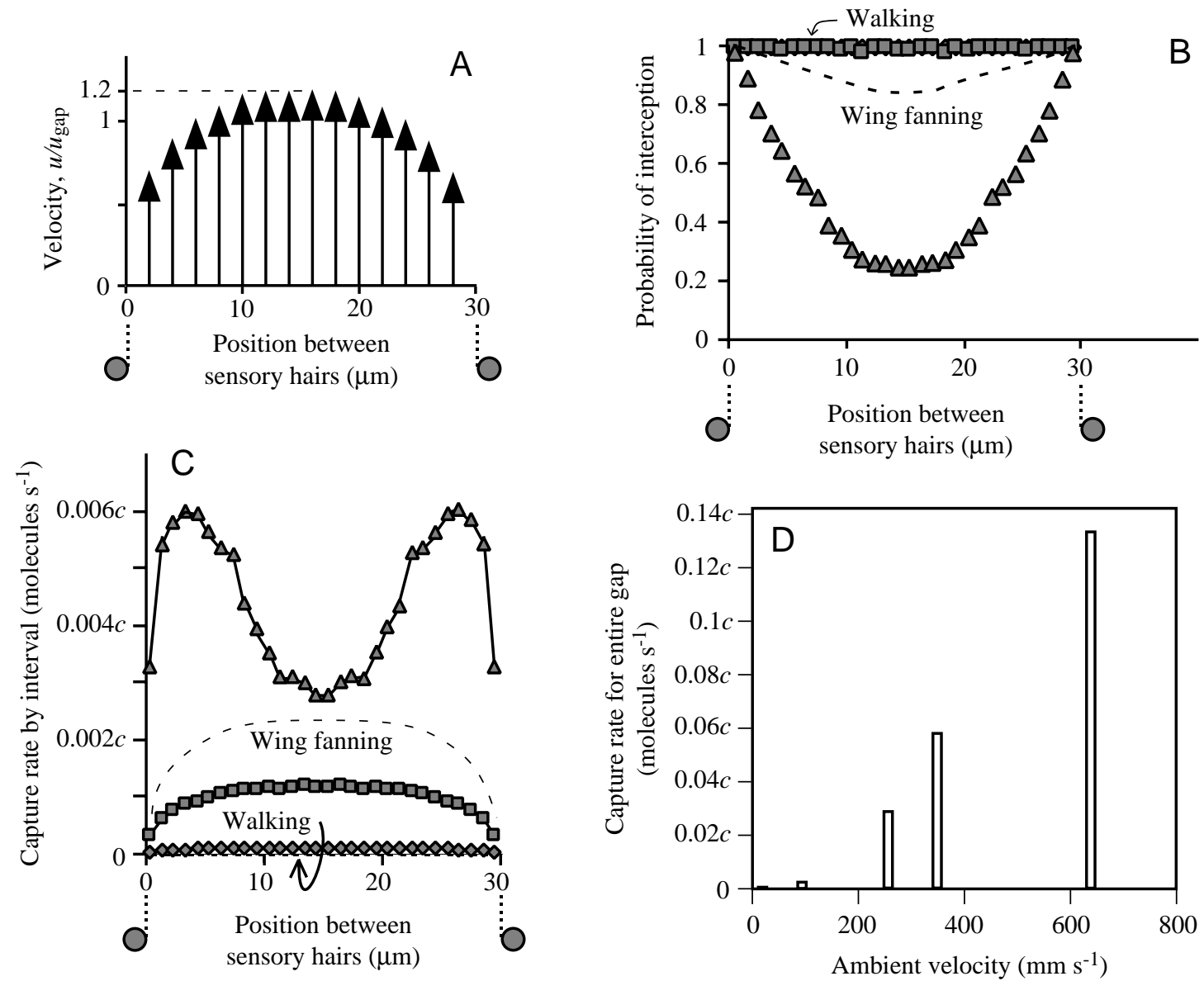

\begin{tabular}{rrrl} 
& $\begin{array}{c}u_{\mathrm{gap}} \\
\left(\mathrm{mm} \mathrm{s}^{-1}\right)\end{array}$ & $\begin{array}{c}u_{\mathrm{ambient}} \\
\left(\mathrm{mm} \mathrm{s}^{-1}\right)\end{array}$ & Pégap \\
\cline { 2 - 4 } Walking \\
\hdashline-0.039 & 23 & 0.00047 \\
$\diamond$ & 1 & 100 & 0.012 \\
$\mathbf{\square}$ & 10 & 260 & 0.12 \\
Wing fanning -- & 22 & 350 & 0.26 \\
$\Delta$ & 100 & 640 & 1.2
\end{tabular}

Fig. 6. Calculations for hairs $2 \mu \mathrm{m}$ in diameter spaced $30 \mu \mathrm{m}$ apart. (A) Velocity profiles between cylindrical hairs for a given gap:diameter ratio (here 15:1) have the same shape for a Reynolds number, $R e$, of less than 0.1 ( $R e$ is calculated using the mean flow between the hairs for the characteristic velocity and the hair diameter for the characteristic length). Here, $u$ is velocity at a given position normalized by $u_{\mathrm{gap}}$, the mean velocity between the hairs. (B) In faster ambient air flow, there is a lower probability of any chemical signal molecule being intercepted by either of two sensory hairs as it passes between them. Furthermore, in faster ambient air flow, the probability of interception becomes more strongly influenced by location between the hairs, with the molecules in the middle of the gap becoming more likely to pass between the hairs without interception. (C) In faster air flow, there is a higher overall interception rate of chemical signal molecules passing through the gap. When the flow is fast enough (such as $100 \mathrm{~mm} \mathrm{~s}^{-1}$ through the gap), the molecules in the middle of the gap are less likely to be sampled. (D) The capture rate for the entire gap (by the two adjacent sensory hairs) increases nonlinearly with ambient velocity. The initial (uniform) concentration of the molecules is $c$ (molecules $\mathrm{mm}^{-3}$ ). 
velocity is fast than when it is slow (Fig. 6B), faster air carries more molecules through the gap per unit time. Thus, the anticipated capture rate of molecules increases with increasing air speed despite the declining efficiency of interception (Fig. 6C). The spatial sampling of the air in the interval also changes with air speed. In air flow rates predicted for wing fanning or slower, the gap between adjacent sensory hairs is fairly evenly sampled. In contrast, in faster air flows (e.g. $100 \mathrm{~mm} \mathrm{~s}^{-1}$ ), the molecules entering the gap close to the hairs are far more likely to be intercepted than are those near the middle of the gap (Fig. 6C).

\section{Discussion}

Effects of wing fanning on sampling of air-borne odors

Wing fanning by a male silk moth, Bombyx mori, draws air across the antennae in an anterior-to-posterior direction. As the air approaches the moth and speeds up to $0.3-0.4 \mathrm{~m} \mathrm{~s}^{-1}$ just upstream of the antennae, the streamlines move closer together (principle of continuity; see Vogel, 1994). Therefore, the air current produced by fanning is funnel-shaped, permitting the moth to sample an area in front of itself much wider than the span of its antennae. The generation of funnel-shaped 'chemical information currents' by appendage movements has also been observed in marine crustaceans (e.g. copepods, lobsters) (for a review, see Atema, 1985). As a male silk moth searches for females, it walks around and turns while it fans its wings (Kanzaki, 1998). Such turning should enable the moth to sample funnels of air from different directions as it searches.

Our flow visualizations showed that wing fanning did not mix the air as it arrived at the antennae; therefore, spatial heterogeneities in the odor signal are not stirred by fanning. Although early analyses of odor plumes treated them as evenly diffusing clouds (see Bossert and Wilson, 1963), measurements of tracer molecules downstream from a release point have shown that environmental air motion swirls and deforms filaments of high concentration of odorant rather than evenly dispersing odorant molecules (see Murlis and Jones, 1981; Murlis, 1986; Murlis et al., 1990, 1992). It has been suggested that animals might use the filament structure in odor plumes to assess their distance from an odor source (see Atema, 1996; Finelli et al., 1999). Behavioral evidence demonstrates that small-scale (of the order of millimeters) heterogeneities in concentration are perceptible to moths following trails of sex pheromone (Kramer, 1986, 1992; Mafra-Neto and Cardé, 1994; Vickers and Baker, 1997; Baker et al., 1998).

\section{Effects of wing fanning on rates of molecule arrival at the surfaces of sensory hairs on antennae}

The sites of chemical signal interception on the antennae of moths are the chemosensory hairs (sensilla), which are often borne on rows on larger branches. Detailed morphological studies of B. mori antennae (Steinbrecht, 1970, 1973) as well as ultrastructural and electrophysiological studies of this and related species (Keil, 1982, 1984; Gnatzy et al., 1984; Steinbrecht and Gnatzy, 1984; Steinbrecht and Muller, 1991; Pophof, 1997) have shown that most of the more than 20000 sensory hairs on an antenna of a $B$. mori adult male are cylindrical trichodea that are sensitive to sex pheromone emitted by the female. Previous estimates of air flow around and molecule interception by a moth sensillum have assumed a single infinitely long hair (Adam and Delbrück, 1968; Murray, 1977), although Murray (1977) pointed out that the flow near a sensillum surrounded by others would be slower than around an isolated cylinder. In contrast, our analysis uses the technique of Cheer and Koehl (1987a) for calculating velocity profiles between small hairs in a row borne on larger branches in a row to estimate the flow between sensilla on the feathery antennae of B. mori. This technique predicted a leakiness of $6 \%$ for the feathery antennae of the luna moth Actias luna (Cheer and Koehl, 1987a), which matches measurements of leakiness for antennae of this species (Vogel, 1983).

The effect of the velocity of the fluid impinging on a hair array of finite width on the flow through the gaps between hairs in the array is non-linear (Cheer and Koehl, 1987b; Koehl, 1995, 1996, 1998). In the case of B. mori, the difference between air penetration through the antennae on a moth fanning its wings compared with a moth walking without fanning is profound. Although wing fanning produces air flow that is approximately 15 times faster than that generated by walking at top speed $\left(0.023 \mathrm{~m} \mathrm{~s}^{-1}\right.$; Kramer, 1986), the air flow through the gaps between the sensilla is predicted to be approximately 560 times faster during fanning (Fig. 6). This increase in air velocity near the sensilla leads to a much greater pheromone interception rate (Fig. 6C,D) during fanning than during walking, even though a smaller proportion of the molecules in the air passing between the sensilla have time to diffuse to them during fanning (Fig. 6B).

In the absence of air flow around a sensory hair, the hair can deplete the air space immediately surrounding it of signal molecules if the molecules that diffuse to the hair are removed from the air by the hair. Such removal is probably a reasonable assumption for insect sensilla, since no release of adsorbed signal molecules is observed and most signal molecules are broken down after transduction (Kaissling, 1998). For example, in still air, a sensory hair $2 \mu \mathrm{m}$ in diameter can encounter by diffusion enough molecules to deplete a 'nominal volume' of air around itself $15 \mu \mathrm{m}$ thick in just over $10^{-4} \mathrm{~s}$, and $100 \mu \mathrm{m}$ thick in $10^{-2} \mathrm{~s}$ (computed for the case of a single isolated cylinder from equation 5.81, Crank, 1975; 'nominal volume' is the cylindrical volume surrounding the cylindrical hair that would be filled by the total number of molecules adsorbed, assuming the initial homogeneous concentration in air). The rate at which a single sensory hair exhausts the volume around it by diffusion in the absence of flow decreases over time as the remaining molecules tend to be farther from the hair on average. Unlike a solitary hair, a sensory hair within an array in still air stops intercepting signal molecules more abruptly once its sampling area overlaps with areas already 


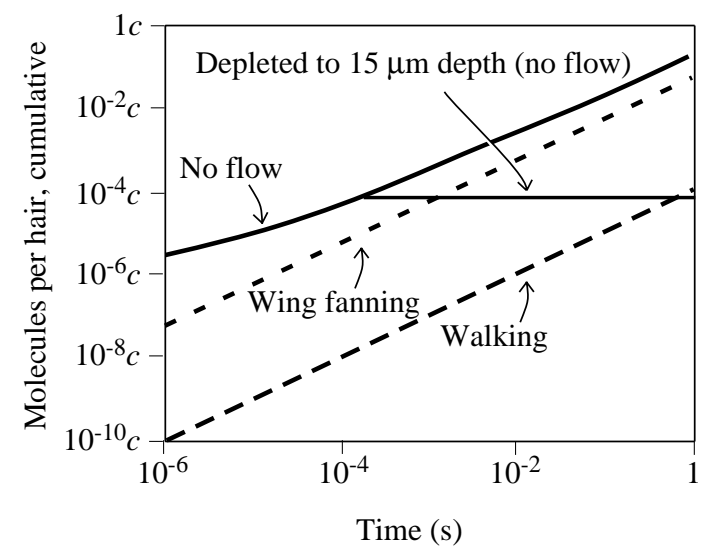

Fig. 7. Over very short time intervals (such as $1 \mu$ s), the cumulative interception of pheromone molecules by a hair $(2 \mu \mathrm{m}$ in diameter, $100 \mu \mathrm{m}$ long) by diffusion in the absence of flow (the 'no flow' line) greatly exceeds the quantity of chemical signal molecules that would have passed within a $30 \mu \mathrm{m}$ gap between hairs in the same time interval during either walking or wing fanning (shown by the dashed lines; average velocities within the gap are assumed to be 0.039 and $22 \mathrm{~mm} \mathrm{~s}^{-1}$, respectively). However, within a short time in the absence of flow (approximately $0.1 \mathrm{~ms}$ ), a perfectly adsorbing hair depletes the molecules to a 'nominal depth' of $15 \mu \mathrm{m}$ in the air completely surrounding the hair (see text). For hairs in a regular array separated by $30 \mu \mathrm{m}$ gaps, this depletion of the air would halt the molecule capture (shown here as a horizontal line). In contrast, the air flow produced by wing fanning supplies more molecules passing through the gap after approximately $1 \mathrm{~ms}$ than would be captured simply by interception of diffusing molecules in the absence of any flow, assuming depletion as described. The initial (uniform) concentration of the molecules is $c$ (molecules $\mathrm{mm}^{-3}$ ).

depleted by its neighbors. In the case of $B$. mori sensilla, with a gap width of approximately $30 \mu \mathrm{m}$, this abrupt decrease in the rate of molecule interception occurs when the "nominal volume' of air around a sensillum that is depleted of odorant reaches a thickness of approximately $15 \mu \mathrm{m}$ (Fig. 7; the "no flow' line bifurcates, with the lower branch of the line indicating the cumulative molecules captured by a sensillum in an array with a $30 \mu \mathrm{m}$ gap width between sensilla, as described below, and the upper branch indicating the cumulative molecules captured by a solitary hair).

The rates of odorant molecule interception by a sensillum on an antenna in still air versus the interception from the gap between hairs due to moving air during walking (at $0.023 \mathrm{~m} \mathrm{~s}^{-1}$ ) or wing fanning (at $0.35 \mathrm{~m} \mathrm{~s}^{-1}$ ) are shown in Fig. 7 plotted as a function of the time interval over which the number of molecules intercepted is integrated. (These rates for walking and wing fanning were calculated assuming that the initial distribution of odorant molecules in the air is uniform, that the sensilla do not begin to remove molecules from the air until time zero, and that molecules are only captured from the air in the gaps between neighboring sensilla.) During the first $1 \mu \mathrm{s}$, only a small volume of air has time to move between the sensilla, whether the moth is fanning its wings or walking, whereas a hair in still air rapidly takes up the molecules surrounding it on all sides (the 'no flow' line in Fig. 7). Hence, for these short time periods and slow flows, the interception rate for the sensory hairs is adequately approximated by diffusion alone, and the negligible component due to convection between the hairs (dashed lines) may be ignored. However, in less than $1 \mathrm{~ms}$ in the absence of air flow, sensilla that are $30 \mu \mathrm{m}$ apart deplete the spaces between them of odorant and do not accumulate any more molecules until they diffuse to the sensilla from air outside this depleted volume. The cessation of molecule capture is indicated by the horizontal line segment in Fig. 7 (the solution for a regular array of cylinders spaced $30 \mu \mathrm{m}$ apart in two dimensions). The actual interception rate for a sensillum increases slightly after the gaps between hairs have been depleted. The time intervals over which chemosensory hairs integrate the number of odorant molecules captured is difficult to characterize, but times of the order of $1 \mathrm{~s}$ are usually assumed (see Atema, 1988; Baker and Vogt, 1988; Dusenbery, 1992). For an integration time of approximately $1 \mathrm{~s}$, wing fanning results in odorant interception rates approximately two orders of magnitude higher than those in still air. In contrast, for an integration time of approximately $1 \mathrm{~s}$, the air flow due to walking has little effect on the molecule encounter rate of the sensillum.

\section{Comparison of wing fanning and flight}

Wing motions made by insects that are not flying are commonly called 'wing fanning'. Many cases of wing fanning represent responses to pheromone stimuli (Sanders, 1986; Charlton and Cardé, 1990), as we observed for male B. mori. We have been unable to find published measurements of the kinematics of wing fanning by lepidopterans (although a dorsal view of wing fanning by B. mori is given by Kanzaki, 1998), but an illustration of hive-ventilation fanning by honeybees (Apis mellifera; Herbst and Freund, 1962) shows the wing tips tracing figure-of-eight paths, as we observed for fanning $B$. mori. For both the silkworm moth and the honeybee, such fanning produces an air current from the anterior towards the posterior of the animal. The wing motions used by $A$. mellifera during such fanning differ in both stroke plane angle and amplitude from those used during flight or during odor dissemination (Pringle, 1975; Nachtigall, 1976).

Neither male nor female $B$. mori fly, so we cannot compare the wing kinematics of fanning versus flying for this species. However, we can compare features of the wings of fanning $B$. mori with those reported for other species of lepidopterans in flight. The wing loading of $\mathrm{B}$. mori (mean value $7.2 \mathrm{~Pa}$ for males; Table 1) is similar to that of other moths (summarized in Brodsky, 1994), and the aspect ratio of B. mori wings (2.5-2.6) falls within the range typical for lepidopterans (Dudley and Srygley, 1994). The mean wingbeat frequency (42 $\mathrm{Hz}$ ) of fanning $B$. mori also lies in the middle of the range reported for other lepidopterans when flying $(17-70 \mathrm{~Hz}$; Brodsky, 1994). As in flying moths (Brodsky, 1994), the wings of fanning $B$. mori touch dorsally and sweep through a large stroke angle; at the end of the downstroke, the wings nearly touch the substratum if the silkworm moth is standing or 
walking, but sweep down even further through a greater stroke angle if the animal is suspended in the air. Furthermore, the fastest rearward air movement produced by fanning $B$. mori occurs during the wing upstroke, while the maximum thrust produced by flying moths (Wilkin and Williams, 1993) and butterflies taking off from the ground (Sunada et al., 1993) also occurs during the upstroke.

\section{Effects of antenna morphology on air flow and molecule capture rates}

Several morphological attributes of an antenna are expected to influence the flow between the sensory hairs arrayed upon it. For a B. mori antenna, the leakiness should be particularly sensitive to the magnitude of the gap between the main branches, $h$, both because it is raised to the third power (equation 4), but also because that gap size is similar in magnitude to the diameter of the adjacent branches that create the gap. Gap:diameter ratios close to 1 commonly show transitional fluid mechanical behavior in empirical and theoretical studies (see Kirsch and Fuchs, 1967; Cheer and Koehl, 1987b; Leonard, 1992; Grünbaum et al., 1998). For example, in the case of B. mori antennae, a twofold difference in branch spacing of 100 versus $200 \mu \mathrm{m}$ between the main branches (approximately $90 \mu \mathrm{m}$ in diameter) makes a 10-fold difference in the predicted leakiness (Fig. 8A,B). Nonetheless, this is not expected to translate directly into a 10 -fold difference in interception rate (Fig. 8D) because more of the molecules approaching the larger gap are expected to pass through without being intercepted (Fig. 8C).

The spacing between sensilla has a much smaller effect on the molecule-interception rate than does the spacing between branches. For example, if the spacing between the sensory hairs is doubled (from 30 to $60 \mu \mathrm{m}$ ), leakiness increases by only approximately $50 \%$ ( $L K_{\mathrm{S}}$ increases by approximately $50 \%$; Fig. 5A in Cheer and Koehl, $1987 \mathrm{~b}$, while $L K_{\mathrm{B}}$ will stay constant, see equation 5), while the proportion of molecules passing through the gap that are intercepted decreases. Nonetheless, molecule flux to a sensillum is increased if gap width, and hence air velocity, is greater because faster air carries more molecules per unit time through the gap. However, a doubling of the gap width between sensilla results in a halving of the total number of these sensory hairs on an antenna of a given area and branch number; therefore, the total capture rate (the sum of the molecules captured by all the sensory hairs on the antenna per unit time) is lower for an antenna with widely spaced hairs than for an antenna with closely spaced hairs, even though the array of widely spaced hairs is leakier to fluid flow. In contrast, if the spacing between sensilla is decreased by a factor of 3, the leakiness is only halved, while the proportion of molecules passing through the gap that are intercepted increases slightly. However, this reduction in gap width between hairs triples the number of hairs on the antenna, thereby increasing overall molecule capture rate. Thus, in the $R e$ range in which moth antennae operate, if two antennae of the same area and branch spacing are exposed to the same oncoming air velocity, the flux of molecules to an individual sensillum is greater for the leakier antenna with more widely spaced sensilla, but the total number of molecules captured per unit time by the entire antenna is greater for the one with more closely spaced hairs.

The geometry used for our calculations is a simplification of that seen in real B. mori antennae. Although the gap width between the larger branches has a particularly large influence on leakiness, branch gap widths in B. mori adult males fall
Fig. 8. The predicted flow between sensory hairs is particularly sensitive to the distance between the main branches. (A) Much faster flow is expected between adjacent sensory hairs arrayed on branches $200 \mu \mathrm{m}$ apart than on branches separated by 100 or $150 \mu \mathrm{m}$. (B) The predicted leakiness between adjacent sensory hairs increases dramatically (10-fold) for a twofold change in distance between the main branches. (C) The proportion of molecules moving through the gap between adjacent sensory hairs is expected to decrease by a factor of approximately 3 when the distance between the main branches is increased twofold. (D) The expected capture rate is proportional to both leakiness (B) and the proportion of molecules intercepted (C) and shows an overall expected increase with larger distances between the main branches. The initial (uniform) concentration of the molecules is $c$ $\left(\right.$ molecules $\mathrm{mm}^{-3}$ ). The diameter of the branches is $90 \mu \mathrm{m}$, the diameter of the sensory hairs is $2 \mu \mathrm{m}$ and the length of the sensory hairs is $100 \mu \mathrm{m}$. Ambient velocity is $350 \mathrm{~mm} \mathrm{~s}^{-1}$.
A
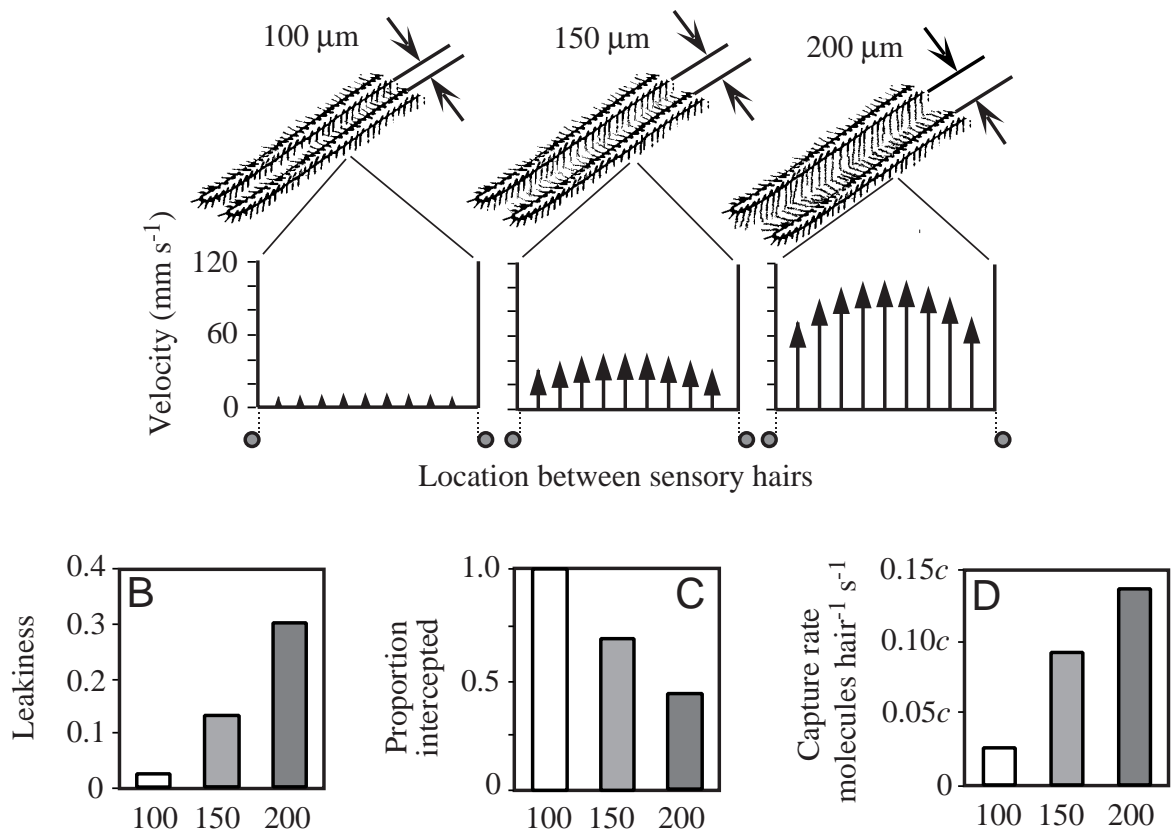

Distance between larger branches $(\mu \mathrm{m})$ 
within a narrow range of approximately $100-150 \mu \mathrm{m}$ both between the antennae of different individuals and among the branches on the same antenna (the branches are not perfectly parallel, smooth or rigid; Fig. 1). Therefore, we chose an intermediate value for branch width of $125 \mu \mathrm{m}$ for most of our calculations. The real sensilla are not parallel, but are splayed apart at their tips. B. mori sensilla are approximately $20 \mu \mathrm{m}$ apart at their bases (along the longitudinal axis of the branch) and can be as much as $40 \mu \mathrm{m}$ apart at their tips (estimated from figures in Steinbrecht, 1970). Therefore, we chose an intermediate gap distance of $30 \mu \mathrm{m}$ for calculation of the velocity profiles. There are more than two hairs in the real antenna, and they are not infinitely long; therefore, real antennae should be slightly leakier than predicted by our theoretical estimates (Hansen and Tiselius, 1992; Leonard, 1992; Koehl, 1996). Furthermore, B. mori sensilla are not perpendicular to ambient flow but project slightly upstream into the flow. However, flows through cylindrical arrays at these low Reynolds numbers tend to pass by the cylinders at right angles even if the undisturbed upstream flow is at some other angle with respect to the cylinders (Tamada and Fujikawa, 1959). Adam and Delbrück (1968) suggest that the interception rate for cylindrical hairs at these low Reynolds numbers will be relatively insensitive to their orientation with respect to the ambient flow.

\section{Unsteady flow generated by wing fanning}

The discussion above ignores the unsteady component of the generated air movement. Whether the unsteady component of air flow affects the velocity profiles adjacent to the sensory hairs, and hence affects the rate of chemical signal interception, is a function of the dimensionless Womersley number, Wo:

$$
W o=R \sqrt{\frac{n}{v}}=\frac{L}{2} \sqrt{\frac{2 \pi f}{v}},
$$

where $L$ is the characteristic length in $\mathrm{m}$ (and $R$ is radius or half-width in $\mathrm{m}), f$ is the frequency of the unsteady component in $\mathrm{Hz}$ (and $n=2 \pi f$ is the angular frequency in $\operatorname{rad~s}^{-1}$ ) and $v$ is the kinematic viscosity in $\mathrm{m}^{2} \mathrm{~s}^{-1}$. For internal (bounded) flow when $W o<1$, the flow is quasi-steady, i.e. the flow will 'track' the pressure gradient in time (Womersley, 1955; Vogel, 1994; Loudon and Tordesillas, 1998). Substituting relevant values for B. mori antennae (where $L$ is the gap width between hairs or branches) into equation 7 results in a prediction that the flow through antennae is quasi-steady in the gaps between hairs or branches. This means that both the flow rate between adjacent sensory hairs and the rate of chemical signal interception oscillates, the latter by as much as a factor of 1.5 at the frequency of $40 \mathrm{~Hz}$. However, it is unlikely that the sensory hairs (or the higher processing centers) are capable of resolving such rapid changes in signal interception rates. Intracellular recordings from moth neurons have demonstrated that chemical stimuli delivered up to $10 \mathrm{~Hz}$ can still be recognized as discontinuous (Christensen and Hildebrand, 1988; Rumbo and Kaissling, 1989), comparable with the temporal characteristics of other arthropod sensory hairs (see Gomez and Atema, 1996).

Wing fanning by any insect has the potential to increase the air flow in the vicinity of its antennae, thus modifying the chemical sampling of its environment. The transition from diffusion-dominated $(P e ́<1)$ to convection-dominated $(P e ́>1)$ flow in the air spaces between sensory hairs could potentially occur in any pectinate antenna, although the air speed relative to the antenna at which this transition occurs is a function of the antennal anatomy (sensory hair diameter, spacing and arrangement; branch diameter, spacing and arrangement; overall length and width of the antenna) and, hence, may vary among species. For non-pectinate insect antennae, the functional consequences to odor capture of an increase in air flow by wing fanning should depend in part on whether transitions in fluid behavior (such as the development of vortices, which is currently under investigation) are triggered by the increase in air velocity. Other sources of increased air flow in the vicinity of insect antennae, such as wind, flight or antennal movements, may also potentially modify the chemical sampling. In general, an increase in air flow would be expected to result in an increase in the rate of chemical signal interception, but this relationship is likely to be highly nonlinear and dependent on the spatial distribution of the chemical signal molecules.

\section{Olfactory antenna design: transitions in leakiness enhance}

$$
\text { sniffing }
$$

In addition to moths, a variety of other arthropods also capture odor molecules from the environment using olfactory appendages that bear arrays of chemosensory hairs. For example, many malacostracan crustaceans (such as lobsters, stomatopods and crabs) flick olfactory antennules bearing arrays of chemosensory hairs through the surrounding water. As in the case of moth sensillae, the olfactory hairs on these crustacean antennules operate within a range of $R e$ values in which changes in velocity or in hair spacing can have profound effects on the flow near the hairs and, thus, on their performance in capturing odor molecules from the surrounding fluid. Therefore, by increasing the fluid velocity encountered by an olfactory appendage (e.g. via flicking in lobsters, stomatopods and crabs or by wing fanning in moths) or by changing the hair spacing (e.g. by passive splaying of hairs during the flick in crabs), the animals can cause dramatic increases in the penetration of ambient fluid between their chemosensory hairs and, thus, in the flux of odor molecules to the surfaces of these hairs (Koehl, 2000).

This research was supported by Office of Naval Research Grants (no. N00014-90-J-1357 and N00014-98-0775 to M.K.), an Erna and Victor Hasselblad Foundation Grant (to M.K. and C.L.), a National Science Foundation Grant (no. GER-9350101, to C.L.), an Eloise Gerry Fellowship from SDE Graduate Women in Science (to C.L.), a John D. and Catherine T. MacArthur Foundation Fellowship Award (to M.K.) and a General Research Fund grant from the University 
of Kansas (to C.L.). This material is based upon work supported by the National Science Foundation under Grant No. EPS-9874732 and matching support from the state of Kansas. We thank Drs R. J. Full and R. Kram for the use of and assistance using their high-speed video-recording equipment and A. Cheer for the use of her unpublished velocity profiles (seen in Fig. 6). Fig. 1 was drawn by $P$. Thompson. Constructive comments from two anonymous reviewers are appreciated.

\section{References}

Adam, G. and Delbrück, M. (1968). Reduction of dimensionality in biological diffusion processes. In Structural Chemistry and Molecular Biology (ed. A. Rich and N. Davidson), pp. 198-215. San Francisco: W. H. Freeman.

Atema, J. (1985). Chemoreception in the sea: adaptations of chemoreceptors and behaviour to aquatic stimulus conditions. Soc. Exp. Biol. Symp. 39, 387-423.

Atema, J. (1988). Distribution of chemical stimuli. In Sensory Biology of Aquatic Animals (ed. J. Atema, R. R. Fay, A. N. Popper and W. N. Tavolga), pp. 29-56. New York: SpringerVerlag.

Atema, J. (1996). Eddy chemotaxis and odor landscapes: exploration of nature with animal sensors. Biol. Bull. 191, 129-138.

Baker, T. C. and Cardé, R. T. (1979). Analysis of pheromonemediated behavior in male Grapholitha molesta, the oriental fruit moth (Lepidoptera: Tortricidae). Env. Ent. 8, 956-968.

Baker, T. C., Fadamiro, H. Y. and Cosse, A. A. (1998). Moth uses fine tuning for odour resolution. Nature 393, 530.

Baker, T. C. and Vogt, R. G. (1988). Measured behavioural latency in response to sex-pheromone loss in the large silk moth Antheraea polyphemus. J. Exp. Biol. 137, 29-38.

Berg, H. C. (1993). Random Walks in Biology. Princeton, NJ: Princeton University Press.

Bossert, W. H. and Wilson, E. O. (1963). The analysis of olfactory communication among animals. J. Theor. Biol. 5, 443-469.

Brodsky, A. K. (1994). The Evolution of Insect Flight. Oxford: Oxford University Press.

Charlton, R. E. and Cardé, R. T. (1990). Orientation of male gypsy moths, Lymantria dispar (L.), to pheromone sources: the role of olfactory and visual cues. J. Insect Behav. 3, 443-469.

Cheer, A. Y. L. and Koehl, M. A. R. (1987a). Fluid flow through filtering appendages of insects. IMA J. Math. Appl. Med. Biol. 4, 185-199.

Cheer, A. Y. L. and Koehl, M. A. R. (1987b). Paddles and rakes: fluid flow through bristled appendages of small organisms. $J$. Theor. Biol. 129, 17-39.

Christensen, T. A. and Hildebrand, J. G. (1988). Frequency coding by central olfactory neurons in the sphinx moth Manduca sexta. Chem. Senses 13, 123-130.

Crank, J. (1975). The Mathematics of Diffusion. New York: Oxford University Press.

Denman, K. L. (1975). Spectral analysis: a summary of the theory and techniques. Fish. Mar. Serv. Tech. Rep. No. 539, 1-28.

Dethier, V. G. (1987). Sniff, flick and pulse: an appreciation of interruption. Proc. Am. Phil. Soc. 131, 159-176.

Dudley, R. and Srygley, R. B. (1994). Flight physiology of neotropical butterflies: allometry of airspeeds during natural free flight. J. Exp. Biol. 191, 125-139.
Dusenbery, D. B. (1992). Sensory Ecology; How Organisms Acquire and Respond to Information. New York: W. H. Freeman.

Finelli, C. M., Pentcheff, N. D., Zimmer-Faust, R. K. and Wethey, D. S. (1999). Odor transport in turbulent flows: constraints on animal navigation. Limnol. Oceanogr. 44, 1056-1071.

Fuchs, N. A. (1964). The Mechanics of Aerosols. New York: Pergamon Press.

Futrelle, R. P. (1984). How molecules get to their detectors: the physics of diffusion of insect pheromones. Trends Neurosci. 7, 116-120.

Gleeson, R. A., Carr, W. E. S. and Trapido-Rosenthal, H. G. (1993). Morphological characteristics facilitating stimulus access and removal in the olfactory organ of the spiny lobster, Panulirus argus: insight from the design. Chem. Senses 18, 67-75.

Gnatzy, W., Mohren, W. and Steinbrecht, R. A. (1984). Pheromone receptors in Bombyx mori and Antheraea pernyi. II. Morphometric analysis. Cell Tissue Res. 235, 35-42.

Gomez, G. and Atema, J. (1996). Temporal resolution in olfaction: stimulus integration time of lobster chemoreceptor cells. J. Exp. Biol. 199, 1771-1779.

Grünbaum, D., Eyre, D. and Fogelson, A. (1998). Functional geometry of ciliated tentacular arrays in active suspension feeders. J. Exp. Biol. 201, 2575-2589.

Hansen, B. and Tiselius, P. (1992). Flow through the feeding structures of suspension feeding zooplankton: a physical model approach. J. Plankton Res. 14, 821-834.

Herbst, H. G. and Freund, K. (1962). Organ der Deutschen Entomologischen Gesellschaft. Deutsche Ent. Z. 9, 1-28.

Kaissling, K. E. (1971). Insect olfaction. In Handbook of Sensory Physiology, vol. IV, Chemical Senses, part 1, Olfaction (ed. L. M. Beidler), pp. 351-431. Berlin, Heidelberg, New York: Springer.

Kaissling, K. E. (1998). Flux detectors versus concentration detectors: two types of chemoreceptors. Chem. Senses 23, 99-111.

Kanzaki, R. (1998). Coordination of wing motion and walking suggests common control of zigzag motor program in a male silkworm moth. J. Comp. Physiol. A 182, 267-276.

Keil, T. A. (1982). Contacts of pore tubules and sensory dendrites in antennal chemosensilla of a silkmoth: demonstration of a possible pathway for olfactory molecules. Tissue \& Cell 14, 451-462.

Keil, T. A. (1984). Reconstruction and morphometry of silkmoth olfactory hairs: a comparative study of sensilla trichodea on the antennae of male Antheraea polyphemus and Antheraea pernyi (Insecta, Lepidoptera). Zoomorph. 104, 147-156.

Kirsch, A. A. and Fuchs, N. A. (1967). Studies on fibrous aerosol filters. II. Pressure drops in systems of parallel cylinders. Ann. Occup. Hyg. 10, 23-30.

Koehl, M. A. R. (1995). Fluid flow through hair-bearing appendages: feeding, smelling and swimming at low and intermediate Reynolds number. Soc. Exp. Biol. Symp. 49, 157-182.

Koehl, M. A. R. (1996). Small-scale fluid dynamics of olfactory antennae. Mar. Fresh. Behav. Physiol. 27, 127-141.

Koehl, M. A. R. (1998). Small-scale hydrodynamics of feeding appendages of marine animals. Oceanogr. 11, 12-14.

Koehl, M. A. R. (2000). Fluid dynamics of animal appendages that capture molecules: Arthropod olfactory antennae. In Conference Proceedings of the IMA Workshop on Computational Modeling in Biological Fluid Dynamics (ed. L. Fauci and S. Gueron). IMA Series (in press).

Kramer, E. (1986). Turbulent diffusion and pheromone-triggered anemotaxis. In Mechanisms in Insect Olfaction (ed. T. L. Payne, 
M. C. Birch and C. E. J. Kennedy), pp. 59-67. Oxford: Clarendon Press.

Kramer, E. (1992). Attractivity of pheromone surpassed by timepatterned application of two nonpheromone compounds. J. Insect Behav. 5, 83-97.

Leonard, A. B. P. (1992). The biomechanics, autecology and behavior of suspension-feeding in crinoid echinoderms. PhD dissertation, University of California, San Diego, USA.

Loudon, C., Best, B. A. and Koehl, M. A. R. (1994). When does motion relative to neighboring surfaces alter the flow through arrays of hairs? J. Exp. Biol. 193, 233-254.

Loudon, C. and Tordesillas, A. (1998). The use of the dimensionless Womersley number to characterize the unsteady nature of internal flow. J. Theor. Biol. 191, 63-78.

Mafra-Neto, A. and Cardé, R. T. (1994). Fine-scale structure of pheromone plumes modulates upwind orientation of flying moths. Nature 369, 142-144.

Mayer, M. and McLaughlin, J. R. (1991). Handbook of Insect Pheromones and Sex Attactants. Boca Raton, FL: CRC Press.

Murlis, J. (1986). The structure of odour plumes. In Mechanisms in Insect Olfaction (ed. T. L. Payne, M. C. Birch and C. E. J. Kennedy), pp. 27-38. Oxford: Clarendon Press.

Murlis, J., Elkinton, J. S. and Cardé, R. T. (1992). Odor plumes and how insects use them. Annu. Rev. Ent. 37, 505-532.

Murlis, J. and Jones, C. D. (1981). Fine-scale structure of odour plumes in relation to insect orientation to distant pheromone and other attractant sources. Physiol. Ent. 6, 71-86.

Murlis, J., Willis, M. A. and Cardé, R. T. (1990). Odour signals: patterns in time and space. In Proceedings of the Xth International Symposium on Olfaction and Taste, Oslo (ed. K. Doving), pp. 6-17. Oslo: Graphic Communication System.

Murray, J. D. (1977). Reduction of dimensionality in diffusion processes: antenna receptors of moths. In Lectures on NonlinearDifferential-Equation Models in Biology, chapter 3, pp. 83-127. Oxford: Oxford University Press.

Nachtigall, W. (1976). Wing movements and the generation of aerodynamic forces by some medium-sized insects. Symp. R. Ent. Soc. Lond. 7, 31-47.

Pophof, B. (1997). Olfactory responses recorded from sensilla coeloconica of the silkworm Bombyx mori. Physiol. Ent. 22, 239-248.

Press, W. H., Flannery, B. P., Teukolsky, S. A. and Vetterling, W. T. (1988). Numerical Recipes in C: The Art of Scientific Computing. Cambridge: Cambridge University Press.

Pringle, J. W. S. (1974). Locomotion: flight. In The Physiology of Insecta, second edition, vol. 3 (ed. M. Rockstein), pp. 433-476. New York: Academic Press.

Probstein, R. F. (1989). Physicochemical Hydrodynamics: An Introduction. Boston: Butterworth-Heinemann.

Romoser, W. S. and Stoffolano, J. G., Jr (1994). The Science of Entomology. Dubuque: Wm. C. Brown Publishers.

Rumbo, E. R. and Kaissling, K. E. (1989). Temporal resolution of odor pulses by three types of pheromone receptor cells in Antheraea polyphemus. J. Comp. Physiol. A 165, 281-292.

Sanders, C. J. (1986). The role of pheromone concentration in male moth flight behaviour. In Mechanisms in Insect Olfaction (ed. T. L. Payne, M. C. Birch and C. E. J. Kennedy), pp. 117-122. New York: Oxford University Press.
Schlichting, H. (1979). Boundary-Layer Theory. New York: McGraw-Hill.

Schmitt, B. C. and Ache, B. W. (1979). Olfaction: responses of a decapod crustacean are enhanced by flicking. Science 205, 204-206.

Schneider, D. (1964). Insect antennae. Annu. Rev. Ent. 9, 103-122.

Snow, P. J. (1973). The antennular activities of the hermit crab, Pagurus alaskensis (Benedict). J. Exp. Biol. 58, 745-765.

Steinbrecht, R. A. (1970). Zur Morphometrie der Antenne des Seidenspinners, Bombyx mori L.: Zahl und Verteilung der Riechsensillen (Insecta, Lepidoptera). Z. Morph. Tiere 68, 93-126.

Steinbrecht, R. A. (1973). Der Feinbau olfaktorischer Sensillen des Seidenspinners (Insecta, Lepidoptera). Rezeptorfortsätze und reizleitender Apparat. Z. Zellforsch. 139, 533-565.

Steinbrecht, R. A. (1992). Experimental morphology of insect olfaction: tracer studies, X-ray microanalysis, autoradiography and immunochemistry with silkmoth antennae. Microsc. Res. Tech. 22, 336-350.

Steinbrecht, R. A. and Gnatzy, W. (1984). Pheromone receptors in Bombyx mori and Antheraea pernyi. I. Reconstruction of the cellular organization of the sensilla trichodea. Cell Tissue Res. 235, 25-34.

Steinbrecht, R. A. and Muller, B. (1991). The thermo-/ hygrosensitive sensilla of the silkmoth, Bombyx mori: morphological changes after dry- and moist-adaptation. Cell Tissue Res. 266, 441-456.

Sunada, S., Kawachi, K., Watanabe, I. and Azuma, A. (1993). Performance of a butterfly in take-off flight. J. Exp. Biol. 183, 249-277.

Tamada, K. and Fujikawa, H. (1959). The steady flow of viscous fluid at low Reynolds numbers passing obliquely through a plane grid made of equal parallel circular cylinders. J. Phys. Soc., Jap. 14, 202-217.

Vickers, N. J. and Baker, T. C. (1994). Reiterative responses to single strands of odor promote sustained upwind flight and odor source location by moths. Proc. Natl. Acad. Sci. USA 91, 5756-5760.

Vickers, N. J. and Baker, T. C. (1997). Flight of Heliothis virescens males in the field in response to sex pheromone. Physiol. Ent. 22, 277-285.

Vogel, S. (1983). How much air passes through a silkmoth's antenna? J. Insect Physiol. 29, 597-602.

Vogel, S. (1994). Life in Moving Fluids: The Physical Biology of Flow, second edition. Princeton: Princeton University Press.

Welty, J. R., Wicks, C. E. and Wilson, R. E. (1984). Fundamentals of Momentum, Heat and Mass Transfer. New York: John Wiley \& Sons.

Wilkin, P. J. and Williams, M. H. (1993). Comparison of the aerodynamic forces on a flying sphingid moth with those predicted by quasi-steady theory. Physiol. Zool. 66, 1015-1044.

Womersley, J. R. (1955). Method for the calculation of velocity, rate of flow and viscous drag in arteries when the pressure gradient is known. J. Physiol., Lond. 127, 553-563.

Zacharuk, R. Y. (1985). Antennae and sensilla. In Comprehensive Insect Physiology Biochemistry and Pharmacology, first edition, vol. 6 (ed. G. A. Kerkut and L. I. Gilbert), pp. 1-69. New York: Pergamon Press. 